\title{
The Effect of Live Demonstration and Flipped Classroom with Continuous Formative Assessment on Dental Students' Orthodontic Wire-bending Performance
}

\section{Saritha Sivarajan ( $\sim$ saritha@um.edu.my )}

University of Malaya Faculty of Dentistry: Universiti Malaya Fakulti Pergigian 0003-2623-4916

\section{Eunice Xinwei Soh}

University of Malaya Faculty of Dentistry: Universiti Malaya Fakulti Pergigian Nor Nadia Zakaria

University of Malaya Faculty of Dentistry: Universiti Malaya Fakulti Pergigian Yasmin Kamarudin

University of Malaya Faculty of Dentistry: Universiti Malaya Fakulti Pergigian

\section{May Nak Lau}

University of Malaya Faculty of Dentistry: Universiti Malaya Fakulti Pergigian

\section{Aufa D.Bahar}

University of Malaya Faculty of Dentistry: Universiti Malaya Fakulti Pergigian

Norhidayah Mohd Tahir

University of Malaya Faculty of Dentistry: Universiti Malaya Fakulti Pergigian

\section{Wan Nurazreena Wan Hassan}

University of Malaya Faculty of Dentistry: Universiti Malaya Fakulti Pergigian

\section{Mang Chek Wey}

University of Malaya Faculty of Dentistry: Universiti Malaya Fakulti Pergigian

\section{Siti Adibah Othman}

University of Malaya Faculty of Dentistry: Universiti Malaya Fakulti Pergigian

Roziana M.Razi

University of Malaya Faculty of Dentistry: Universiti Malaya Fakulti Pergigian

\section{Zahra Naimie}

University of Malaya Faculty of Dentistry: Universiti Malaya Fakulti Pergigian

\section{Research article}


Keywords: dental education, flipped classroom, formative assessment, live demonstration, orthodontic wire-bending, teaching method

Posted Date: February 17th, 2021

DOI: https://doi.org/10.21203/rs.3.rs-244844/v1

License: (1) This work is licensed under a Creative Commons Attribution 4.0 International License. Read Full License 


\section{Abstract}

Background: In some dental schools, undergraduate students are taught wire-bending to train their manual dexterity. Traditionally, live demonstration (LD) was used as the sole teaching method until recently, either live video demonstration or flipped classroom (FC) teaching are being employed.

Continuous formative assessment can be used as a systematic approach for personalised learning. This allows monitoring of the students' progress and enhances learning by enabling students to identify their strengths and weaknesses. This study aims to evaluate the effects of live demonstration and flipped classroom teaching methods, supplemented with continuous formative assessment on dental students' performances in bending six types of wire components for removable orthodontic appliances. By knowing the effectiveness of the teaching methods, appropriate method can be implemented in view of the current Covid-19 pandemic.

Methods: Forty third-year undergraduate dental students were randomly assigned into FC $(n=20)$ or LD $(n=20)$ cohorts. They attended six teaching sessions, for six types of wire components each, with either LD or FC teaching methods. Submission of wire assignments was required after each session, for blinded wire-bending assessment, which were distributed to the students, lecturers, and technicians before the next session, as part of their formative assessment. Students also completed a self-reported questionnaire after the first session (T0) and at the end of all six sessions (T1).

Results: The mean wire-bending scores for FC was significantly $(p<0.05)$ higher than LD for two of the six assignments, namely the Adams clasp and Z-spring. In LD and FC, formative assessment was found to have contributed a significant increase in scores over time. No statistically significant correlation was found between the wire-bending scores and utilisation of videos. T0 and T1 questionnaires showed that students were satisfied with both teaching methods.

Conclusions: Both LD and FC are equally effective in transferring practical skills of orthodontic wirebending and well-received by students. Continuous formative assessment enhanced students' learning of orthodontic wire-bending skills.

\section{Background}

In some dental schools, undergraduate students are taught wire-bending to train their manual dexterity. Traditionally, live demonstration was used as the sole teaching method until recently, either live video demonstration [1] or flipped classroom teaching [2) are being employed.

Live demonstration (LD) teaching method can increase students' confidence, improve communication skills, and provide better understanding as compared to didactic teaching [3]. However, it has also been associated with factors that decrease teaching effectiveness such as restricted view during demonstrations involving larger groups, limited repeatability due to time constraints, and the burden of manpower needed for every demonstration session [2]. To overcome these limitations, Alqahtani et al. (2015) suggested using procedural video demonstrations. They found that students performed equally 
well in their wire-bending skills, although students who had video demonstration felt the steps presented were clear and easy to understand compared to those who had LD.

In flipped settings, students access teaching contents online before class, enabling interactive and collaborative activities during class to promote learning [4]. Flipped classroom (FC) provides a flexible platform for self-paced learning which helps to improve students' learning interest [5]. Thus, it enhances personalised learning by allowing students to access resources to learn at their own preferred pace, way, and location. A meta-analysis comparing this approach to traditional teaching methods among various health education profession, concluded a significant improvement in student learning with the employment of FC [6]. However, considering the varied student learning styles and personality types, there was a suggestion to develop a more tailored teaching style for increased effectiveness in medical and dental education. This led to a need for personalised monitoring of student learning in FC method [7].

Continuous formative assessment can be used as a systematic approach for personalised learning. This allows monitoring of the students' progress and enhances learning by enabling students to identify their strengths and weaknesses. It also enables teachers to identify students who are struggling early in the course and thus, address their learning needs without delay [8].

To the best of our knowledge, no study investigated the effects of live demonstration and flipped classroom, supplemented with continuous formative assessment during the undergraduate teaching of orthodontic wire-bending. Thus, this study aims to evaluate the effects of live demonstration and flipped classroom teaching methods supplemented with continuous formative assessment on dentals students' performance in bending six types of wire components for removable orthodontic appliances.

\section{Objectives:}

This study embarks on the following objectives:

1. To compare students' orthodontic wire-bending scores between two cohorts: FC and LD teaching methods

2. To analyse the association of continuous formative assessment with orthodontic wire-bending scores of FC and LD cohorts over the six wire-bending sessions

3. To investigate the frequency and co-relation between usage of online video demonstration with students' orthodontic wire-bending scores

4. To compare student's perceived satisfaction on wire-bending demonstration for both cohorts: FC and LD teaching methods

\section{Methods}

This was a prospective study conducted at the Faculty of Dentistry, University of Malaya from October 2019 to February 2020. Ethics approval was granted by the Medical Ethics Committee, Faculty of 
Dentistry, University of Malaya (DR CD1918/0106 (L).

The entire class of forty third-year undergraduate dental students in 2019 with no previous exposure to orthodontic wire-bending were informed and consented to participate in this study. At the beginning of the academic year, all students were randomly divided into four groups of ten students. All students consented for this study after understanding the study objectives and flow. The group leaders picked a sealed envelope containing the demonstration method ( $L D$ or FC) to randomly assign the groups either into a FC cohort $(n=20)$ or LD cohort $(n=20)$. For both cohorts, the skills of wire-bending were taught in a standardised manner with identical steps and standardised rubrics for each wire-bending. They were taught to bend six wire components for removable orthodontic appliances in the following order - Adams clasp, buccal canine retractor, palatal finger spring, Southend clasp, Z-spring, and Hawley labial bow. Students in each allocation cohorts were divided into smaller sub-groups to ensure the lecturer to student and technician to student ratio was 1:10. Figure 1 shows the flow chart of the study.

\section{Sample Size Calculation}

Sample size calculation was based on known population. Since the population of interest to be used within this study was 40 undergraduate students who comprised the entire third-year class of 2019, thus, it was decided to invite the whole class. After voluntary informed consent the class was then divided into two equal numbered cohorts of students.

\section{Study Cohorts}

\section{Cohort 1 (Live Demonstration)}

The LD was conducted by calibrated technicians with ten students encircling each technician in the presence of a lecturer. Students are free to ask questions during the LD and the technicians repeated the wire-bending steps whenever necessary. An ideally wire for each type of component was given to the students as a reference model during the sessions. LD sessions were scheduled a week prior to FC sessions to avoid exposure to flipped teaching videos. After every demonstration session, the LD students were given a week to fabricate and submit their wire-bending product for blinded quality assessment. As part of continuous formative assessment, the scores and marking rubric of each type of wire component were returned to the students who scored below sixty per cent., as well as to the lecturers and technicians, before the next session. This enables the students to ascertain their learning progress and use the opportunity improve where necessary in the upcoming teaching session. A sixty per cent passing grade was set as an indicator of the minimum knowledge and skills required for the fabrication of orthodontic wire components [2]. Teachers (technicians and lecturers) monitors closely the students who scored below par in subsequent LD sessions. These was repeated for all the lessons involving the six types of wire components.

\section{Cohort 2 (Flipped Classroom)}


Demonstration videos for all the six wires were pre-recorded by the same calibrated technicians who conducted LD. These videos were then posted for the FC group on the university's online learning platform once the LD group had submitted their task for each type of the wires. The FC group similarly had a week to view the video and practice wire-bending for the component assigned, prior to their teaching session. During the teaching session, students were free to ask the technician questions and to refer to the ideally wire. Students were required to apply the knowledge that they comprehended from watching the videos and submit their wire-bending product for blinded quality assessment at the end of the teaching session. During this session, similar method of continuous formative assessment was employed for this cohort.

All submissions from both cohorts were blinded for grading using codes of numbers from 1 to 40, allocated by one of the researchers who was not involved in the grading. Each type of wire was graded by the same examiner.

\section{Error in Methods}

To eliminate any variation in the teaching and assessment, the lecturers and technicians had multiple calibration sessions on each item of the rubrics and on every wire-bending component, prior to the video recording, demonstration sessions and grading. Rubrics for all the six wire components were based on specific criteria ensuring the best efficiency of the fabricated component, in relation to the purpose of the components and with the least complication when utilised within an orthodontic removable appliance as required in our curriculum (Table 1). A score of one was given for each item of the rubrics if the wire bending criteria was achieved and zero when not achieved. The total marks for each type of wire component were than scaled over ten regardless of the number of items in each rubric. To ensure reproducibility of the marks, every type of the wire components from both cohorts were graded by one orthodontist and the intra-observer calibration for six assessors was undertaken by repeating the marking on ten wires two weeks apart prior to the final grading.

\section{Questionnaire}

A validated self-reported questionnaire adapted from Lau et al. (2019), was distributed to the students after the submission of the first wire component (T0) and the last wire component (T1) to assess their preference and satisfaction towards their learning experience [9]. The questionnaire consisted of demographic questions followed by twenty-nine items grouped under six domains: (1) Infrastructure and materials provided; (2) Demonstration method; (3) Teaching method; (4) Wire-bending task; (5) Teaching efficiency; (6) and Overall satisfaction. Responses were recorded using a 5-point Likert scale from strongly agree(score 1) to strongly disagree (score 5), where lower scores would indicate stronger agreement. The T1 questionnaire had additional questions for the FC cohort to assess their usage and perception of the videos.

\section{Statistical Analysis}


Statistical Package for Social Sciences (SPSS) Version 25.0 was used to analyse the quantitative data. Intra-examiner reliability was tested using Intraclass Correlation Coefficient (ICC). Normality was tested using Shapiro-Wilk test. The scores of wire-bending were normally distributed. Scores for the six types of wire-bending components between the two cohorts were assessed using independent t-test. A one-way repeated measure analysis of variance (RMANOVA) was conducted to analyse separately the orthodontic wire-bending scores for FC and LD cohorts with continuous formative assessment over the six wirebending sessions. Descriptive statistics were used to report the usage of the video. Spearman's correlation was used to test the association of video usage to students' wire-bending skills. Independent ttest and Mann-Whitney U test was used to compare student's perceived satisfaction of teaching methods on wire-bending demonstration for normally and not normally distributed data, respectively. The alpha level of significance was set at 0.05 .

\section{Results}

The intra-examiner ICC for all the six examiners was greater than 0.90 indicating excellent agreement within the examiners for each of the six components.

Thirteen (32.5\%) male and 27 (67.5\%) female students participated in this study. The average age was $21.8( \pm 0.2)$ years. Thirty-eight (95\%) were right-handed and only two (5\%) were left-handed.

Comparison of the mean of the wire-bending scores are presented in Table 2. The mean wire-bending scores for FC was statistically significant $(p<0.05)$ for two of the six components, namely the Adams clasp and Z-spring. There was no significant difference in the mean scores for other components between the two cohorts.

Pairwise comparisons of wire-bending scores with the implementation of formative assessment for both cohorts are presented in Table 3. Both LD and FC cohorts showed significant increase in wire-bending scores over the six wire bending exercises $\operatorname{LD}(F(3.589,68.190)=38.550, P<0.0001), \operatorname{FC}(F(3.132$, $59.509)=19.917, P<0.0001)$ ]. Follow-up comparisons indicated that most pairwise differences were statistically significant $(p<0.05)$ for both cohorts. However, with Bonferroni adjustment, for both cohorts, no significant differences were found in their orthodontic wire-bending scores between certain wire combinations as shown in Table 2.

Table 4 shows the frequency of the students in FC cohort in utilising the wire-bending videos. There was a mixed distribution of students who watched the videos in their full length, repeated watching or used the playing features of the video and practised the wire-bending procedures alongside the videos. In terms of their satisfaction with the quality of the videos, there were also reports of inadequate access, lack of satisfaction with the videos, and preferences for videos from other sites. Table 4 also shows the correlation between the students' total wire-bending scores with the way they utilised the videos. Watching the entire length of the videos and students' preference to watch other videos than what was uploaded on their online learning platform had a moderate correlation with the total wire-bending scores $(r=0.384 ; r=0.396)$ but was not statistically significant $(p>0.05)$. Watching the videos before the wire- 
bending session had negative moderate correlation (-0.361), which was not statistically significant $(p>$ $0.05)$ too. Overall, no statistically significant correlation was found between the wire-bending scores and utilisation of videos.

Student's perceived satisfaction on wire-bending demonstration for both cohorts are presented in Table 5 . T0 questionnaire showed that both cohorts were satisfied with their learning methods, with positive mean scores for all domains. However, there was a significant difference between LD and FC cohorts for two domains; demonstration method video/ live $(p<0.0001)$; and wire-bending task $(p=0.005)$. Both were in favour of LD. At T1, overall positive satisfaction with LD and FC was maintained. The LD cohort expressed higher favour for the demonstration method received $(p=0.003)$ and overall satisfaction with the teaching method $(p=0.011)$. However, the FC cohort was significantly more satisfied with the infrastructure and materials received $(p<0.0001)$.

\section{Discussion}

The present study showed the effectiveness of personalised learning for teaching wire-bending skills either as LD or FC method. The FC method appeared to be the more effective way of teaching orthodontic wire-bending skills for two of the six components - Adams clasps and Z-spring. The former was the first wire tasked to learn by the inexperienced and unskilled students while the latter was one of the most complicated components to bend. Within the similar one-week submission deadline, the FC cohort had access to view the video demonstration and practise throughout the week before the classroom session and were able to attend the said session with prepared questions and some amount of acquired wirebending skills. However, for the LD cohort, they could only ask questions during the two-hour classroom session where they watched the demonstration for the first time, and this was followed by a week of selfpractice without any video guidance. Meanwhile, for the remaining four types of components, which may have required less wire-bending skills, our findings were in agreement with previous studies reporting that both LD and FC are equally effective in transferring the skills of orthodontic wire-bending [2]. The intergroup difference between the mean scores for Adams clasp and Z-spring were statistically significant but these values were not clinically significant.

In the present study, the students' performances improved over successive tasks regardless of the teaching method. This suggested that formative assessment significantly improved students' wirebending skills for both settings. Formative assessment promoted personalised learning by providing feedback to the teachers and students to make any required improvement [8]. Students received their individual score and grade after each wire-bending session, which were also disseminated to the lecturers and laboratory technicians prior to the next demonstration session and enabled them to identify and assist students who required extra guidance. It might also have promoted the students to engage in a self-reflective process and work on improving their wire-bending skills [10]. On the other hand, the improved scores might be reflected as a consequence that the students had acquired skills with increasing practice in wire-bending that they were able to improve in performance over time. 
Although all dental schools have some element of formative assessment in their curriculum, the effectiveness of formative assessment was not frequently investigated, let alone for an undergraduate orthodontic course [11]. To the best of our knowledge, the present study was the first to investigate the effectiveness of formative assessment on transferring orthodontic wire-bending skills. Various approaches of formative assessment have been reported to improve dental students' performance on other aspects of dental education, including the structured clinical operative test (SCOT), tutor assessment following problem-based learning, online formative assessment via online exam questions, mini-objective structured clinical examination (mini-OSCE), direct observation of procedural skills (DOPS), and competency-based formative progress assessment system [12-17]. Another new approach that has been attempted and well-received by schools includes a streamlined electronic formative feedback model (FFM) developed by Indiana University School of Dentistry (IUSD) [18]. Multisource feedback from colleagues and patients had been reported to be well-accepted by dental postgraduate students as an effective formative assessment tool to improve on professionalism [18]. The importance of formative assessment has slowly gained considerable attention by both dental schools and students. The result of our study suggested that continuous formative assessment may have an important and positive role in dental education especially in terms of teaching and learning clinical and laboratory skills.

It is observed that certain wire-bending tasks were more difficult and challenging e.g. Southend clasp and Z-spring. This explained the observation where certain pairwise differences on follow up comparisons were not significantly different.

The study demonstrated that instructional videos were not fully optimised by the FC cohort despite the perceived opportunities to learn from the videos at the students' own time and pace. This may be attributed to their preference for learning styles or lack of complete satisfaction with the videos or access to them. Reflection on ways to improve the videos is recommended. Teachers intending to implement the FC method should bear in mind the challenges of implementing such instructional method. Even though not all FC students fully optimised the videos, the use of the videos had no association with their performance. It might be that the students picked up the concepts of the wire-bending through watching parts that they needed to learn and not necessarily the whole prepared video. These students also had opportunities to ask the teachers during the classroom sessions, which might have helped them understand concepts missed from the video. The finding of this study supports that learning is dynamic and can be taught in different ways, including the FC method. Past studies comparing traditional teaching methods with video-based teaching can achieve the same performance from students if the instructions were well-delivered $[2,20,21]$.

Both methods, LD and FC are suitable to teach wire-bending in orthodontics as both were received favourably by the students, although LD was rated significantly higher than FC. Students preferring LD may have been due to the limitation of the videos in presenting a three-dimensional procedure. The videos also did not allow direct engagement between the student and the technician prior to the classroom session. In terms of the tasks given, students initially were inclined towards LD for fabricating their wire components, but later FC was found to be equally accepted. Similarly, only at T1 did the FC 
cohort find the classroom arrangement to be conducive for the given task compared to LD at the end of the exercise. This may indicate that students require some time to familiarise with flipped learning before truly appreciating and embracing this teaching method [22].

\section{Limitation of the study}

Ideally, a control group with students undergoing the orthodontic wire-bending sessions without formative assessment should be included to investigate the effectiveness of the formative assessment. However, it was deemed ethically inappropriate to withhold any student from the possible benefit of personalised learning in this cohort.

\section{Recommendation}

A large proportion of the students were not satisfied with the quality of videos provided on their online learning platform and some even favoured other similar videos available online. Even though the quality of the videos had not affected the students' performances, it is recommended to resolve this issue to encourage students to optimise using the videos. Suggestions include involving students during development of educational videos to incorporate elements that would attract the end users. Digital literacy is required for effective video development and further educational technological support is crucial to assist in appropriate video integration in clinical teaching.

\section{Conclusions}

Both live demonstration and flipped classroom are equally effective teaching methods in transferring practical skills of orthodontic wire-bending. Continuous formative assessment and feedback as a form of personalised learning showed positive improvement in acquiring new skills for both cohorts. FC should be viewed as a complement to the $L D$ and a vehicle for achieving the goals of teaching and learning.

\section{Abbreviations}

LD - Live demonstration

FC - Flipped classroom

\section{Declarations}

Ethics approval and consent to participate - Written ethical approval was obtained from Medical Ethics Committee, Faculty of Dentistry, University of Malaya. Reference number: DR CD1918/0106 (L). Written informed consent obtained from all participants. 
Availability of data and material - Yes (The datasets used and/or analysed during the current study are available from the corresponding author on reasonable request)

Competing interests - The authors declare that they have no competing interests

Funding - UM Learning Improvement and Teaching Enhancement Research (UMLiter Grant), University of Malaya (RU013U-2019) provided the fund for this research. The funder just provided the fund for the conduct of this research. The funder was not involved in the design of the study and collection, analysis, interpretation of data and writing of the manuscript.

Authors' contributions - All authors contributed in the initial idea, conception of this study, development of the rubrics, supervision of the wire-bending demonstration sessions, data collection and analysis, drafted specific section of the manuscript based on task distributed by corresponding author and critically reviewed the manuscript. SS lead this study, coordinated the wire-bending demonstration, data collection, analysis, interpretation and delegated the task of manuscript writing among all the members and critically reviewed this manuscript. .

Acknowledgements - The authors would like to acknowledge the technicians who participated in this study. This study was funded by UM Learning Improvement and Teaching Enhancement Research (UMLiter Grant), University of Malaya (RU013U-2019)

\section{Disclosure}

The current study received funding University of Malaya. The authors have no affiliations with or involvement in any organisation or entity with any financial, economic, or professional interests that may have influenced the design, execution or presentation of this scholarly work.

\section{References}

1. Atik E, Gorucu-Coskuner H, Taner T. The Effect of Live-Video Demonstration on Dental Students' Orthodontic Bending Performance. Journal of dental education. 2020; 84(3):377-84. 
2. Alqahtani ND, Al-Jewair T, Khalid AM, Albarakati SF, ALkofide EA. Live demonstration versus procedural video: a comparison of two methods for teaching an orthodontic laboratory procedure. BMC medical education. 2015; 15(1):1-4.

3. Packer ME, Scott BJ, Davis DM. An assessment of the influence of clinical demonstrations on the confidence of undergraduate dental students, when treating patients requiring removable partial dentures. European Journal of Dental Education. 1999; 3(3):133-139.

4. Park SE, Howell TH. Implementation of a flipped classroom educational model in a predoctoral dental course. Journal of dental education. 2015; 79(5):563-70.

5. Bishop JL, Verleger MA. The flipped classroom: A survey of the research. In ASEE national conference proceedings, Atlanta, GA; 2013. 30(9):1-18.

6. Hew KF, Lo CK. Flipped classroom improves student learning in health professions education: a meta-analysis. BMC medical education. 2018; Dec 1;18(1):38.

7. Kim M, Roh S, Ihm J. The relationship between non-cognitive student attributes and academic achievements in a flipped learning classroom of a pre-dental science course. Korean Journal of Medical Education. 2018 Dec;30(4):339.

8. Patrick S, Kennedy K, Powell A. Mean What You Say: Defining and Integrating Personalized, Blended and Competency Education. International Association for K-12 Online Learning. 2013.

9. Lau MN, Yasmin K, NorNadia Z, Saritha S, Norhidayah MT, Aufa DB, Wan Nurazreena WH, Mang Chek, Wey, Siti Adibah O, Zahra N. Flipped Classroom Using E-Learning for Undergraduate Orthodontic Wire-bending Teaching: Students' Perception. (Poster presented at: 1st International Conference on Digital Solution for Education and Clinical Dentistry (ICDSECD). 2019; November 1819, Kuala Lumpur, Malaysia)

10. Rolfe I, McPherson J: Formative assessment: how am I doing? The Lancet. 1995; 345(8953):837-9.

11. Atkin P A, Willis A, Doncahie C, Elledge RO, Thomas SJ, Ni Riordain R, Galvin S, Marmey C, Setterfield JF, Smith PM, Hammond D. Human Disease/Clinical Medical Sciences in Dentistry: Current state and future development of undergraduate assessments in the UK and Ireland.European Journal of Dental Education. 2020.

12. Mossey PA, Newton JP. The structured clinical operative test (SCOT) in dental competency assessment. British Dental Journal; 2001. 190:387-390.

13. Bearn DR, Chadwick SM, Jack AC, Sackville A. Orthodontic undergraduate education: assessment in a modern curriculum. European Journal of Dental Education. 2002; 6(4): 162-168.

14. Olson, B. L., \& McDonald, J. L. Influence of online formative assessment upon student learning in biomedical science courses. Journal of Dental Education. 2004; 68(6),656-659.

15. Lele SM. A mini-OSCE for formative assessment of diagnostic and radiographic skills at a dental college in India. Journal of dental education. 2011; 75(12):1583-1589.

16. Henly DC. Use of Web-based formative assessment to support student learning in a metabolism/nutrition unit. European Journal of Dental Education. 2003; 7(3):116-122. 
17. Akbari M, Mahavelati Shamsabadi R. Direct observation of procedural skills (dops) in restorative dentistry: Advantages and disadvantages in student's point of view. Iranian Journal of Medical Education. 2013; 13(3):212-220.

18. Kirkup ML, Adams BN, Meadows ML, Jackson R. Development and implementation of an electronic clinical formative assessment: dental faculty and student perspectives. Journal of Dental Education. 2016; 80(6):652-661.

19. Carounanidy U, Sethuraman KR, Nilakantan A, Narayan KA. Multisource feedback in dental postgraduation: A qualitative research. Journal of Contemporary Medical Education. 2017; 5(1):11.

20. Kaur K, Singh NV, Ghai S, Agnihotri M. A comparative study to assess the effectiveness of live demonstration and video-assisted teaching on nasogastric tube feeding on the skill development of nursing students. Nursing and Midwifery Research. 2015;11(4).

21. Maria R, Kaur D, Jaspal S. Comparing video-assisted teaching (VAT) versus self-instructional module (SIM) regarding care of ventilated patients on knowledge and practices of staff nurses. Journal of Nursing and Midwifery Research. 2015; 11 (1): 12.

22. Lo CK, Hew KF. A critical review of flipped classroom challenges in K-12 education: Possible solutions and recommendations for future research. Research and Practice in Technology Enhanced Learning. 2017 12(1):4.

\section{Tables}

Table 1: Assessment criteria for Adams clasp, buccal canine retractor, palatal finger spring, Southend clasp, Z-spring and Hawley labial bow. 


\section{ASSESSMENT CRITERIA}

Adams Clasp

1. The bridge of the clasp should be straight

2. The bridge of the clasp should parallel to the buccal cusp

3. The bridge of the clasp shouldn't touch the buccal surface of the 1st molar

4. The height of the bridge of the clasp should be at halfway up the buccal surface of the molar

5. The mesial arrowhead should be at $45^{\circ}$

6. The distal arrowhead should be at $45^{\circ}$

7. The mesial arrowhead should engage the mesio-buccal undercut

8. The distal arrowhead should engage the disto-buccal undercut

9. The mesial arm of the clasp should follow the occlusal embrasure

10. The distal arm of the clasp should follow the occlusal embrasure

11. The mesial arm of the clasp should touch the occlusal embrasure

12. The distal arm of the clasp should touch the occlusal embrasure

13. When the mesial arm goes on the palatal tissue, there should be about $0.5 \mathrm{~mm}$ to 1 $\mathrm{mm}$ clearance

14. When the distal arm goes on the palatal tissue, there should be about 0.5 to $1 \mathrm{~mm}$ clearance

15. The mesial arm should be bend towards palate in a mesial direction

16. The distal arm should be bend towards palate in a mesial direction

17. The mesial tag should be facing towards the palate

18. The distal tag should be facing towards the palate

Buccal canine retractor
1. $\quad 0.5-1.5 \mathrm{~mm}$ away from buccal side of alveolar mucosa

2. Coil at least $2 \mathrm{~mm}$ away from sulcus and coil height preferably at or above root apex

3. Mesial/active arm along the long axis of canine, mid-crown width

4. Coil diameter 2-3 $\mathrm{mm}$

5. There is no gap within the helix coil

6. Coil situated distal to mesial/active arm

7. Coil resting on top of mesial/active arm

8. Horizontal retraction end of the mesial/active arm starts perpendicular to the mesial/active arm 
9. Horizontal retraction end of the mesial/active arm curves along crown curvature to the level of mesial contact point of canine

10. Small safety coil present at end of mesial/active arm

11. Small safety coil tucked/folded tightly at end of mesial/active arm

12. Small safety coil at end of mesial/active arm adapted to mesial surface interproximally

13. Distal/retentive arm follow occlusal embrasure between second premolar and first molar

14. Distal/retentive arm touch occlusal embrasure between second premolar and first molar

15. When the palatal retention arm goes on the palatal tissue, there should be about

0.5 to $1 \mathrm{~mm}$ clearance

16. Retention tag should be facing towards the palate

Palatal finger spring

1. The diameter of the helix coil is $2-3 \mathrm{~mm}$

2. There is no gap within the helix coil

3. The retentive arm should be at least $4 \mathrm{~mm}$

4. The coil should be bent in the opposite direction of planned tooth movement

5. The coil should be placed on the slope of palatal vault region.

6. When the retentive arm goes on the palatal tissue, there should be about $0.5 \mathrm{~mm}$ to $1 \mathrm{~mm}$ clearance

7. The tag should be facing towards the palate

8. Active arm is positioned perpendicular to tooth movement direction

9. Small safety coil at end of active arm

10. Small safety coil at end of active arm adapted to mesial surface inter-proximally

11. The guard wire is $10-15 \mathrm{~mm}$ in length. It should follow the amount of tooth movement required (eg. distance from mesial of canine to distal of 1st premolar)

12. Tag ends of guard wire is $1-2 \mathrm{~mm}$ and in same direction

Southend clasp
1. The wire should follow the contour of the cervical margin of UR1 and UL1 on the labial side with a small U-loop in between the central incisor

2. The wire should be 0-1 $\mathrm{mm}$ away from the gingiva

3. The wire should touch the tooth surface

4. The right arm of the clasp should touch the occlusal embrasure

5. The left arm of the clasp should touch the occlusal embrasure 
6. The wire should follow the contour of the cervical margin of UR1 and UL1 on the palatal side until the mesial third of the incisor

7. The right retentive arm should start at the mesial third of the incisor with a perpendicular bend towards the palate

8. The left retentive arm should start at the mesial third of the incisor with a perpendicular bend towards the palate

9. The distance between the two retentive arms should be at least $2 \mathrm{~mm}$

10. The right tag should be facing towards the palate

11. The left tag should be facing towards the palate

12. When the right arm goes on the palatal tissue, there should be about $0.5 \mathrm{~mm}$ to 1 $\mathrm{mm}$ clearance

13. When the left arm goes on the palatal tissue, there should be about 0.5 to $1 \mathrm{~mm}$ clearance

Z-spring 1. Small safety coil at end of active arm

2. The active arm is straight

3. The width of z-spring should be equal to the mesio-distal width of the lateral incisor

4. The active arm should be gingival to the first helix

5. The diameter of the first helix coil is $2-3 \mathrm{~mm}$

6. There is no gap within the first helix coil

7. The second helix should be gingival to the first helix

8. The diameter of the second helix coil is $2-3 \mathrm{~mm}$

9. There is no gap within the second helix coil

10. The spring should be perpendicular to the mid-palatal surface of the lateral incisor

11. When the retentive arm goes on the palatal tissue, there should be about 0.5 to 1 $\mathrm{mm}$ clearance

12. The tag should be facing towards the palate

Hawley labial bow
1. The labial segment of the wire should be placed at the middle third of the incisors

2. The right mesial vertical segment of the wire should start from the mesial third of the right canine

3. The left mesial vertical segment of the wire should start from the mesial third of the left canine

4. The right mesial vertical segment should be perpendicular $\left(90^{\circ}\right)$ to the labial segment

5. The left mesial vertical segment should be perpendicular $\left(90^{\circ}\right)$ to the labial

Page $16 / 24$ 
segment

6. The right distal vertical segment should be parallel to the mesial vertical segment

7. The left distal vertical segment should be parallel to the mesial vertical segment

8. The right vertical segment should be $0.5-1.5 \mathrm{~mm}$ away from buccal side of alveolar mucosa

9. The left vertical segment should be $0.5-1.5 \mathrm{~mm}$ away from buccal side of alveolar mucosa

10. The vertical height of the right loop should be $2-3 \mathrm{~mm}$ above the gingival margin

11. The vertical height of the left loop should be $2-3 \mathrm{~mm}$ above the gingival margin

12. The right retentive arm should follow the occlusal embrasure

13. The left retentive arm should follow the occlusal embrasure

14. The right retentive arm should touch the occlusal embrasure between the right canine and first premolar

15. The left retentive arm should touch the occlusal embrasure between the left canine and first premolar

16. When the right retentive arm goes on the palatal tissue, there should be about 0.5 to $1 \mathrm{~mm}$ clearance

17. When the left retentive arm goes on the palatal tissue, there should be about 0.5 to $1 \mathrm{~mm}$ clearance

18. The right tag should be facing towards the palate

19. The left tag should be facing towards the palate

Table 2: Comparison between mean wire-bending scores obtained for six orthodontic components with LD and FC teaching methods. 


\begin{tabular}{|llll|}
\hline \multirow{2}{*}{ Orthodontic component } & \multicolumn{2}{c|}{ Mean Wire Bending Score (SD) (Max score = 10) } & p-value \\
\cline { 2 - 4 } & $\begin{array}{l}\text { Live demonstration cohort } \\
(\mathrm{n}=20)\end{array}$ & $\begin{array}{l}\text { Flipped classroom cohort } \\
(\mathrm{n}=20)\end{array}$ & \\
\hline Adams clasp & $4.58 \pm 1.80$ & & \\
\hline Buccal canine retractor & $8.58 \pm 0.99$ & $8.94 \pm 0.64$ & $0.00^{\star}$ \\
\hline Palatal finger spring & $9.33 \pm 1.10$ & $9.11 \pm 0.68$ & 0.18 \\
\hline Southend clasp & $6.33 \pm 1.41$ & $7.13 \pm 1.76$ & 0.45 \\
\hline Z-spring & $7.54 \pm 1.61$ & $8.88 \pm 0.99$ & 0.13 \\
\hline Hawley labial bow & $9.26 \pm 1.22$ & $8.90 \pm 0.81$ & $0.03^{\star}$ \\
\hline
\end{tabular}

${ }^{*} \mathrm{p}<0.05$, based on independent sample t-test

Table 3: Pairwise Comparisons of wire bending scores with the implementation of formative assessment in the LD and FC cohorts 


\section{Type of Wire}

Adams Clasp

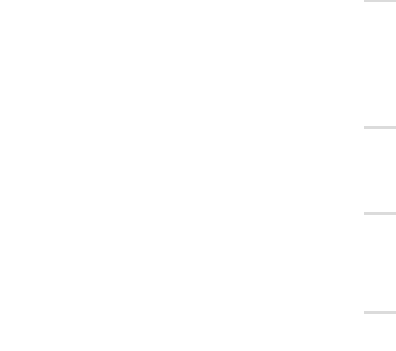

Buccal canine retractor

Mean score

Difference \pm SD

Sig. $\quad$ Mean score

Difference \pm SD

Sig.

$-4.00 \pm 0.43^{*}$

retractor

Palatal finger
spring

$-4.75 \pm 0.48$ *

Southend clasp

$-1.75 \pm 0.55$

0.07

$-1.75 \pm 0.55$

$0.00^{\#}-2.96 \pm 0.51^{*}$

$0.00^{\#} \quad-4.68 \pm 0.45^{\star}$

Hawley Labial

$-2.96 \pm 0.51^{\star}$

$-4.68 \pm 0.45^{\star}$

bow

Adams Clasp

$4.00 \pm * 0.43$

$-0.75 \pm 0.24$

Palatal finger

spring

Southend clasp

Z-spring

$1.04 \pm 0.40$

$-0.68 \pm 0.36$

Hawley Labial

bow

Palatal finger

spring

\begin{tabular}{|c|c|c|c|c|}
\hline Adams Clasp & $4.75 \pm 0.48$ * & $0.00^{\#}$ & $4.75 \pm 0.48^{*}$ & $0.00^{\#}$ \\
\hline $\begin{array}{l}\text { Buccal canine } \\
\text { retractor }\end{array}$ & $0.75 \pm 0.24$ & 0.10 & $0.75 \pm 0.24$ & 0.10 \\
\hline Southend clasp & $3.00 \pm 0.42^{\star}$ & $0.00^{\#}$ & $3.00 \pm 0.42^{\star}$ & $0.00^{\#}$ \\
\hline Z-spring & $1.79 \pm 0.45^{\star}$ & $0.01^{\#}$ & $1.79 \pm 0.45^{\star}$ & $0.01^{\#}$ \\
\hline $\begin{array}{l}\text { Hawley Labial } \\
\text { bow }\end{array}$ & $0.07 \pm 0.40$ & 1.00 & $0.07 \pm 0.40$ & 1.00 \\
\hline Adams Clasp & $1.75 \pm 0.55$ & 0.07 & $1.75 \pm 0.55$ & 0.07 \\
\hline $\begin{array}{l}\text { Buccal canine } \\
\text { retractor }\end{array}$ & $-2.25 \pm 0.40 *$ & $0.00^{\#}$ & $-2.25 \pm 0.40 *$ & $0.00^{\#}$ \\
\hline $\begin{array}{l}\text { Palatal finger } \\
\text { spring }\end{array}$ & $-3.00 \pm 0.42^{\star}$ & $0.00^{\#}$ & $-3.00 \pm 0.42^{\star}$ & $0.00^{\#}$ \\
\hline Z-spring & $-1.21 \pm 0.47$ & 0.27 & $-1.21 \pm 0.47$ & 0.27 \\
\hline $\begin{array}{l}\text { Hawley Labial } \\
\text { bow }\end{array}$ & $-2.93 \pm 0.24^{\star}$ & $0.00^{\#}$ & $-2.93 \pm 0.24 *$ & $0.00^{\#}$ \\
\hline
\end{tabular}




\begin{tabular}{|c|c|c|c|c|c|}
\hline \multirow[t]{5}{*}{ Z-spring } & Adams Clasp & $2.96 \pm 0.51^{\star}$ & $0.00^{\#}$ & $2.96 \pm 0.51^{\star}$ & $0.00^{\#}$ \\
\hline & $\begin{array}{l}\text { Buccal canine } \\
\text { retractor }\end{array}$ & $-1.04 \pm 0.40$ & 0.26 & $-1.04 \pm 0.40$ & 0.26 \\
\hline & $\begin{array}{l}\text { Palatal finger } \\
\text { spring }\end{array}$ & $-1.79 \pm 0.45^{\star}$ & $0.01^{\#}$ & $-1.79 \pm 0.45^{\star}$ & $0.01^{\#}$ \\
\hline & Southend clasp & $1.21 \pm 0.47$ & 0.27 & $1.21 \pm 0.47$ & 0.27 \\
\hline & $\begin{array}{l}\text { Hawley Labial } \\
\text { bow }\end{array}$ & $-1.72 \pm 0.47 *$ & $0.02^{\#}$ & $-1.72 \pm 0.45^{\star}$ & $0.02^{\#}$ \\
\hline \multirow{5}{*}{$\begin{array}{l}\text { Hawley Labial } \\
\text { bow }\end{array}$} & Adams Clasp & $4.68 \pm 0.45^{\star}$ & $0.00^{\#}$ & $4.68 \pm 0.45^{\star}$ & $0.00^{\#}$ \\
\hline & $\begin{array}{l}\text { Buccal canine } \\
\text { retractor }\end{array}$ & $0.68 \pm 0.31$ & 1.00 & $0.68 \pm 0.36$ & 1.00 \\
\hline & $\begin{array}{l}\text { Palatal finger } \\
\text { spring }\end{array}$ & $-0.07 \pm 0.40$ & 1.00 & $-0.07 \pm 0.40$ & 1.00 \\
\hline & Southend clasp & $2.93 \pm 0.24^{*}$ & $0.00^{\#}$ & $2.93 \pm 0.24^{\star}$ & $0.00^{\#}$ \\
\hline & Z-spring & $1.72 \pm 0.45^{\star}$ & $0.02^{\#}$ & $1.72 \pm 0.45^{\star}$ & $0.02^{\#}$ \\
\hline
\end{tabular}

Based on estimated marginal means

*Significant difference

1. Adjustment for multiple comparisons: Bonferroni.

${ }^{\#} \mathrm{P}<0.01(0.05 / 5)$

Table 4: Frequency of the $\mathrm{FC}$ cohort $(\mathrm{N}=20)$ in utilising the wire bending videos and Correlation between the total wire bending score with students' utilisation of videos. 


\begin{tabular}{|c|c|c|c|c|c|c|c|}
\hline \multirow[t]{3}{*}{ Activity } & \multicolumn{5}{|c|}{ Frequency (\%) } & \multirow{3}{*}{$\begin{array}{l}\text { Spearman's } \\
\text { rho }\end{array}$} & \multirow{3}{*}{$\begin{array}{l}p- \\
\text { value }\end{array}$} \\
\hline & Never & Seldom & Sometimes & Frequently & Always & & \\
\hline & $\begin{array}{l}\text { (0 } \\
\text { video) }\end{array}$ & $\begin{array}{l}(1-2 \\
\text { videos) }\end{array}$ & (3 videos) & $\begin{array}{l}\text { (4-5 } \\
\text { videos) }\end{array}$ & $\begin{array}{l}\text { (all } 6 \\
\text { videos) }\end{array}$ & & \\
\hline \multicolumn{8}{|l|}{ USAGE } \\
\hline $\begin{array}{l}\text { I watched the } \\
\text { entire length of } \\
\text { the videos }\end{array}$ & $0(0)$ & $1(5)$ & $3(15)$ & $5(25)$ & $11(55)$ & 0.384 & 0.094 \\
\hline $\begin{array}{l}\text { I watched the } \\
\text { videos more } \\
\text { than once }\end{array}$ & $0(0)$ & $1(5)$ & $4(20)$ & $8(40)$ & $7(35)$ & 0.108 & 0.651 \\
\hline $\begin{array}{l}\text { I watched the } \\
\text { videos before } \\
\text { the classroom } \\
\text { wire bending } \\
\text { session }\end{array}$ & $0(0)$ & $1(5)$ & $3(15)$ & $5(25)$ & $11(55)$ & -0.361 & 0.118 \\
\hline $\begin{array}{l}\text { I watched the } \\
\text { videos during } \\
\text { the classroom } \\
\text { wire bending } \\
\text { session }\end{array}$ & $2(10)$ & $7(35)$ & $7(35)$ & $2(10)$ & $2(10)$ & 0.009 & 0.968 \\
\hline $\begin{array}{l}\text { I practised wire } \\
\text { bending while } \\
\text { watching the } \\
\text { videos }\end{array}$ & $0(0)$ & $1(5)$ & $1(5)$ & $6(30)$ & $12(60)$ & 0.108 & 0.651 \\
\hline $\begin{array}{l}\text { I practised wire } \\
\text { bending before } \\
\text { the classroom } \\
\text { wire bending } \\
\text { session }\end{array}$ & $1(5)$ & $3(15)$ & $4(20)$ & $4(20)$ & $8(40)$ & 0.133 & 0.575 \\
\hline $\begin{array}{l}\text { I used the pause, } \\
\text { fast forward and } \\
\text { rewind functions } \\
\text { while watching } \\
\text { the videos }\end{array}$ & $3(15)$ & $2(10)$ & $2(10)$ & $2(10)$ & $11(55)$ & -0.287 & 0.219 \\
\hline $\begin{array}{l}\text { I watched the } \\
\text { videos with } \\
\text { friends }\end{array}$ & $0(0)$ & $0(0)$ & $0(0)$ & $4(20)$ & $16(80)$ & -0.087 & 0.716 \\
\hline \multicolumn{8}{|l|}{ PERCEPTION } \\
\hline $\begin{array}{l}\text { I am satisfied } \\
\text { with the quality } \\
\text { of the videos }\end{array}$ & $12(60)$ & $5(25)$ & $3(15)$ & $0(0)$ & $0(0)$ & -0.257 & 0.275 \\
\hline $\begin{array}{l}\text { I had difficulty } \\
\text { accessing the } \\
\text { videos on }\end{array}$ & $7(35)$ & $9(45)$ & $1(5)$ & $2(10)$ & $1(5)$ & -0.053 & 0.823 \\
\hline
\end{tabular}


university's

online learning

platform

I prefer to watch

other videos

$1(5)$

$6(30)$

9 (45)

$4(20)$

$0(0)$

0.396

0.084

than what was

uploaded onto

university's

online learning

platform

${ }^{*} p<0.05$ indicates statistical significance

Table 5: Student's perceived satisfaction on wire-bending demonstration after first (T0) and last (T1) wirebending tasks. (Lower scores indicate higher satisfaction) 


\begin{tabular}{|c|c|c|c|c|}
\hline Feedback section & Time & Cohort & $\begin{array}{l}\text { Mean (SD) } \\
N=20\end{array}$ & $\begin{array}{l}\text { p- } \\
\text { value }\end{array}$ \\
\hline \multirow[t]{4}{*}{ Infrastructure and materials provided } & \multirow[t]{2}{*}{ TO } & LD & $2.5(1.1)$ & \multirow[t]{2}{*}{$0.303^{\wedge}$} \\
\hline & & $\mathrm{FC}$ & $2.5(0.6)$ & \\
\hline & \multirow[t]{2}{*}{$\mathrm{T} 1$} & LD & $2.9(0.9)$ & \multirow[t]{2}{*}{$0.000^{\wedge}$} \\
\hline & & $\mathrm{FC}$ & $1.8(0.6)$ & \\
\hline \multirow[t]{4}{*}{ Demonstration method (live / video) } & \multirow[t]{2}{*}{ TO } & LD & $1.8(0.6)$ & \multirow[t]{2}{*}{$0.000 *$} \\
\hline & & $\mathrm{FC}$ & $2.8(0.8)$ & \\
\hline & \multirow[t]{2}{*}{ T1 } & LD & $2.0(0.6)$ & \multirow[t]{2}{*}{$0.003^{*}$} \\
\hline & & $\mathrm{FC}$ & $2.7(0.7)$ & \\
\hline \multirow[t]{4}{*}{ Teaching method } & \multirow[t]{2}{*}{ T0 } & LD & $2.0(0.6)$ & \multirow[t]{2}{*}{$0.708^{\wedge}$} \\
\hline & & FC & $1.9(0.5)$ & \\
\hline & \multirow[t]{2}{*}{ T1 } & LD & $2.0(0.6)$ & \multirow[t]{2}{*}{$0.466^{\wedge}$} \\
\hline & & FC & $2.2(0.6)$ & \\
\hline \multirow[t]{4}{*}{ Wire-bending task } & \multirow[t]{2}{*}{ T0 } & LD & $2.3(0.8)$ & \multirow[t]{2}{*}{$0.005^{\star}$} \\
\hline & & FC & $3.0(0.6)$ & \\
\hline & \multirow[t]{2}{*}{ T1 } & LD & $2.6(0.7)$ & \multirow[t]{2}{*}{$0.436^{\wedge}$} \\
\hline & & $\mathrm{FC}$ & $2.8(0.6)$ & \\
\hline \multirow{4}{*}{$\begin{array}{l}\text { Efficiency of lecturer and technician during the } \\
\text { classroom activity }\end{array}$} & \multirow[t]{2}{*}{ T0 } & LD & $1.7(0.5)$ & \multirow[t]{2}{*}{$0.750^{\wedge}$} \\
\hline & & $\mathrm{FC}$ & $1.7(0.6)$ & \\
\hline & \multirow[t]{2}{*}{$\mathrm{T} 1$} & LD & $1.8(0.4)$ & \multirow[t]{2}{*}{$0.198^{\wedge}$} \\
\hline & & $\mathrm{FC}$ & $1.6(0.5)$ & \\
\hline \multirow[t]{4}{*}{ Overall } & \multirow[t]{2}{*}{ T0 } & LD & $1.9(0.5)$ & \multirow[t]{2}{*}{$0.367^{\wedge}$} \\
\hline & & FC & $2.0(0.5)$ & \\
\hline & \multirow[t]{2}{*}{ T1 } & LD & $1.9(0.3)$ & \multirow[t]{2}{*}{$0.011^{\wedge}$} \\
\hline & & FC & $2.4(0.7)$ & \\
\hline
\end{tabular}

* Independent t-test, ^ Mann-Whitney U test

Figures 


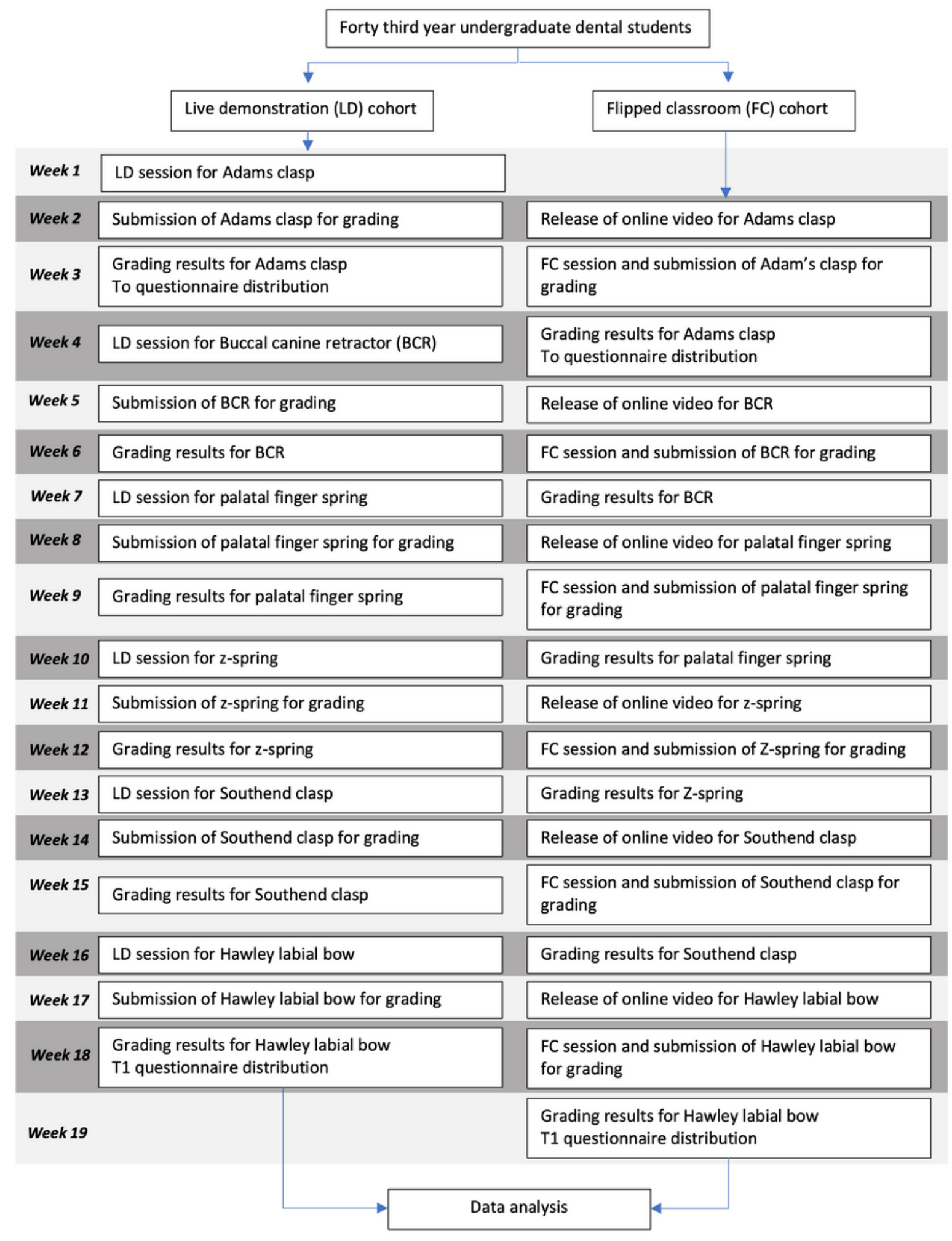

\section{Figure 1}

Flow chart of the study 